\title{
Developing leaders by supporting their transitions into senior positions
}

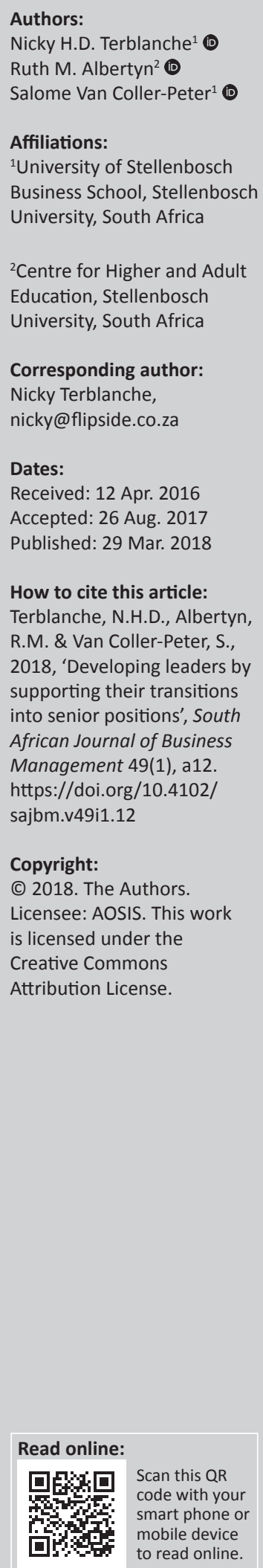

\begin{abstract}
The need for social transformation in South Africa is intrinsically linked to the transformation of corporate South Africa. Strong senior leadership is required to ensure that organisations remain sustainable during this transformation. There is, however, a shortage of skilled senior leaders, hence the need for leadership development. When leaders transition into senior positions, they face a plethora of personal and systemic challenges. Many fail with resulting disastrous effects on individual (micro) and organisational (macro) levels. This research investigates the challenges faced by newly promoted senior leaders in order to lay the groundwork for designing support strategies for individuals and organisations. The qualitative findings suggest that leadership transitions present unexpected challenges on a personal and systemic level to such individuals and that they do not receive adequate support from their organisations. For transformation to be successful and sustainable on macro level, concurrent and appropriate micro-level support and development are essential.
\end{abstract}

\section{Introduction}

In the South African context, the term 'transformation' commonly refers to the imperative for change. The need for redress and development has resulted in policies to fast-track and rectify imbalances, manifesting in changes in many aspects of society (Burger et al. 2015; Chevalier 2015). These changes have opened various opportunities for development and have also spawned the need for development. Therefore, transformation at macro level also has implications for change at micro level. A key site for transformation has been the organisational context through legislation such as affirmative action and the Black Economic Empowerment imperatives (Khunou 2015). Transformation initiatives are not the only driver of career transitions. Individuals' own ambition, need for self-fulfilment and desire to succeed drive them towards taking on more senior positions within organisations (Visagie \& Koekemoer 2014). Transitions into new career positions may provide challenges to employees in organisations and could at times lead to management derailment (Lombardo \& McCauley 1988). While transformation at macro level is laudable, it could hold negative consequences for both the intended beneficiaries of change and the organisation if micro-level transformation does not accompany this transition (Avolio \& Hannah 2008; Watkins 2009). In fact, it may be unethical to enforce such change without providing the necessary professional support to those who are placed in these positions and who are expected to perform in such high-stress contexts. Transformation thus needs to be viewed comprehensively and clarity needs to be gained regarding the theoretical aspects of the concept and the facilitation of sustainable transformation in the South African organisational context.

In addition to the challenges in the South African organisational context, change is a global reality that impacts sustainability. A key element of organisational sustainability is effective leadership at senior levels in particular, yet there is a significant shortage of effective organisational leaders in the world (Dotlich, Noel \& Walker 2004). The fast pace of corporate expansion requires leaders in organisations to move to new leadership levels at increasing speeds, and while many leaders attempt the transition bravely many fail to do so, or underperform (Charan, Drotter \& Noel 2011; Watkins 2003).

Leadership transition occurs when a leader is promoted to a more senior level in the organisation and takes on more and different responsibilities. This poses numerous challenges. The incumbent is expected to 'hit the ground running', deal with higher levels of complexity and uncertainty, exhibit a higher level of emotional intelligence, work with longer time horizons and step out of the comfort zone of a specialist to take on strategic challenges (Goleman 1996; Jaques 1996; Peltier 2010; Sutton 2008). Herein lies the challenge: how can leaders prepare for the transition and what assistance is offered by their organisations to support them for or during transitions towards 
higher leadership levels? A recent McKinsey report (Martin 2015) revealed that the scope of organisational support that transitioning executives receive has a significant impact on the success of their transition. In addition, receiving organisational support during the transition allows them to spend their time and energy understanding the issues that they are able to influence. However, only $27 \%$ of the respondents believed their organisations were doing enough to provide such support.

For South Africa to grow economically, compete effectively on the international economic stage and attain demographically representative senior leadership, it is imperative that organisations provide support to leaders when they transition into senior leadership roles. It is not well known what challenges transitioning leaders face in their new roles and how organisations are supporting the development of leaders during these transitions. With this in mind, the research question that guided this study was: what are the experiences of leaders during transitions into senior positions?

\section{Literature review}

The main theoretical perspective informing this research is leadership development theory and specifically leadership transitions, as illustrated in Figure 1. Leadership development consists of a developmental process where inter- and intrapersonal aspects of the leader are addressed. Leadership transition is an aspect of leadership development and is described by a variety of transition models consisting of challenges faced by the incumbent, various support strategies, and theories and implications of success or failure.

Leadership theory is a complex and diverse topic and no single agreed definition currently exists to describe this phenomenon. More has been written and less is known about leadership than any other topic in behavioural science (Day \& Antonakis 2012). A distinction is made between leader development and leadership development. Leader development concentrates on developing the individual leader, whereas leadership development involves multiple individuals, including the leader, his or her followers and the social impact of this process (Day et al. 2014). A career transition presents challenges to both leader and leadership development and is captured in the notions of intrapersonal and interpersonal areas of development.
Interpersonal development includes aspects such as experience, learning, skills and self-development (Bettin \& Kennedy 1990; Boyce, Zaccaro \& Wisecarver 2010; Mumford, Campion \& Morgeson 2007). Its relevance to career transitions include awareness of the type of experience leaders have before the promotion; encouraging transitioning leaders to remain open to the idea of learning; being cognisant of the types of skills required at the new career level; and awareness of career and work orientations to direct self-development. Interpersonal factors in leadership development are focused on enhancing leadership capacity (Day et al. 2014) and rely on the content and structures of relationships involving leaders (Adler \& Kwon 2002). Two aspects highlighted in the literature are social mechanisms and authentic leadership. Social mechanisms refer to positive learning environments and awareness of social mechanisms that may assist in building strong relationships (Scandura \& Lankau 1996). The systemic contribution of the environment must be taken into consideration during career transitions. Authentic leadership requires self-awareness, self-regulation, openness and trust from both leader and followers (Avolio \& Gardner 2005) and should be fostered during career transitions.

Leadership transitions have received much attention in the popular business and academic press. Often-cited publications include the work of Charan et al. (2011) who brought attention to the notion of leadership transitions through their leadership pipeline model, which describes six leadership passages and the significant challenges faced during each stage. Moving into a senior leadership position is one of the key challenges that leaders need to face during their careers (Dotlich et al. 2004). The concept of a leadership pipeline suggests that changes are required in individuals in terms of their appearance, knowledge, behaviour, attitudes and values as they progress up the ladder (Kaiser et al. 2011). They face a so-called triple challenge of having to decide which aspects of their previous roles they need to let go of, which to preserve and which to build on (Freedman 2011). More generally, challenges faced by transitioning leaders fall into five categories: cognitive, behavioural, interpersonal, psychological and systemic (Bebb 2009; Lombardo \& Eichinger 2002; Manderscheid \& Ardichvili 2008).

A different perspective on leadership levels is Jaques's Stratified Systems Theory, which defines work in organisations in seven strata on a basis of decision-making

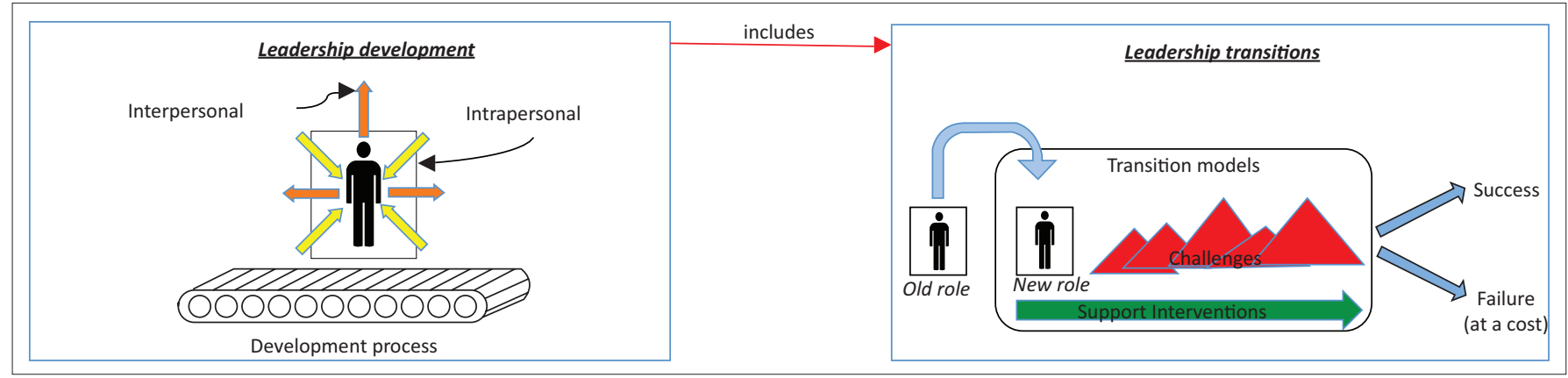

FIGURE 1: Theoretical underpinnings of this research. 
complexity where each level of work is related to the time span required by the executor to complete the task (Jaques 1996). This theory supports the view of Charan et al. that different skills and abilities are required by leaders operating at different levels and it reinforces the view that change and transformation are required to successfully perform at a new level. By implication, then, if a leader is promoted, the leader needs to adapt to the new level and will face challenges in the process.

Leadership transitions are complex and challenging. Many strategies, tools, models and frameworks are provided to help overcome these challenges (Bradford 1995; Charan et al. 2011; Dotlich et al. 2004; Sutton 2008; Watkins 2003). Leadership transition is viewed as a highly significant life event in the career path of an individual and it acts as a handful of triggers that open the opportunity for significant growth and learning, yet organisations rarely have validated general frameworks or theories for leadership development (Avolio \& Hannah 2008:331). By promoting someone who is not well supported before and during the transition, organisations potentially set the individual up for failure, with negative consequences for both the individual and the organisation (Avolio \& Hannah 2008; Watkins 2009). This failure during an upward transition is referred to as 'management derailment', which is the phenomenon where fast-tracked leaders stop advancing before reaching their full potential on their way up the leadership ladder (Denton \& Van Lill 2006; Lombardo \& Eichinger 1995; Lombardo \& McCauley 1988; McCall \& Lombardo 1983; Morrison, White \& Van Velsor 1987).

Newly promoted leaders' ability to learn is a crucial element of their ultimate success (Freedman 2011). Learning can take many forms. At the one end of the spectrum, leaders could merely learn the new tricks of the trade by trying out a number of different approaches to solve a problem, evaluating the outcome and trying a different strategy if not successful. This equates to single-loop learning (Argyris 1991) or merely adapting to the new situation (Poutiatine 2010). On the other end of the spectrum, leaders could examine the deeper governing variables that influence the very nature of their thinking and behaviour. They could re-evaluate and reframe these deep-seated patterns and habits to achieve a more permanent shift in the way they interpret and interact with the world. This type of change is defined as 'double-loop learning' (Argyris 1991) or 'transformative learning' (Mezirow 1994). While potentially daunting, the important personal challenges posed by the transition to a senior management position offers an opportunity for leaders to undergo transformation (Mezirow 2000) instead of mere adaptation (Isopahkala-Bouret 2008). Understanding the challenges newly promoted leaders face may therefore help inform the creation of personal and organisational strategies to effectively support the development of leaders in new positions and to assist with transformation on a personal (micro) and organisational (macro) level.

\section{Methodology Research design}

This research employed constructivist grounded theory principles (Charmaz 2014) to generate a view on the challenges faced by newly promoted senior managers. Purposeful, theoretical sampling, consistent with the requirements of grounded theory research, was used to identify participants (Strauss \& Corbin 1990). Practically, this implied starting with the most likely source of data (recently transitioned senior managers), leading on to coaches who did transition coaching, followed by the custodians of coaching in organisations and concluding with line managers of recently promoted senior managers. This sampling strategy allowed for data collection from multiple perspectives to ensure variety and richness.

In total, 16 people were interviewed: 8 senior managers employed in corporate South Africa who were promoted less than 3 years ago and who received at least six coaching sessions during this period (referred to as P1-P8); five coaches who had coached transitioning leaders, not necessarily linked to the first group (referred to as C1-C5); two human resource managers who coordinated coaching efforts in their organisation (referred to as HR1 and HR2) and one chief executive officer who had witnessed senior leadership transitions (referred to as M1). The participants were interviewed in person or via telephone. Participants were sourced from the extended personal and professional networks of the researchers and included representatives from medium and large listed, privately owned and parastatal organisations. There were an equal number of females and males in the sample.

\section{Data collection}

Interviews lasting approximately $1 \mathrm{~h}$ were conducted between June 2016 and December 2016 with each participant individually. Interviews were digitally recorded, transcribed and analysed. Analysis occurred after each interview to inform the interview strategy for the next participant in accordance with grounded theory principles of constant comparison and theoretical sampling (Charmaz 2014; Goulding 2002).

The interviews followed an open-ended, in-depth format. A basic interview guide was used, which allowed the researcher to enquire of the various categories of participants about job transitions, the challenges faced by the incumbents, what they did to support themselves, how their organisations assisted them in the process and what approaches the coaches used.

\section{Data analysis}

A number of different data analysis options are available in grounded theory (Goulding 2002). In this study, the researchers applied a process based on the recommendation of Charmaz (2014) consisting of line-by-line coding, focused 
coding and category identification through extensive memo writing. Throughout the research the core principles of grounded theory were employed, namely theoretically sensitive coding, constant comparison and theoretical sampling (Glaser \& Strauss 1967). This implied going back into the field to re-interview certain participants as new themes emerged (Strauss \& Corbin 1990). The qualitative analysis software application ATLAS.ti was used to assist with the analysis process.

\section{Data quality and ethics}

To ensure data quality the transcribed interviews were sent back to the participants for member checking (Lincoln \& Guba 1985). A researcher's diary was also kept to help keep track of the research process and to apply reflexivity.

\section{Ethical consideration}

This research received clearance from the University of Stellenbosch Business School's Ethics Committee. All participants signed informed consent documents in which they were made aware of their rights as research participants.

\section{Findings and discussion}

The main objective of this phase of the research was to explore the experiences of leaders as they transitioned into senior roles and the level of support that they had received from their organisations. For the participants interviewed in this research, the process of fulfilling the new position can be filtered down to three subthemes, as illustrated in Figure 2.

Participants had initial impressions of what the role entailed. After taking up the position they faced actual challenges and

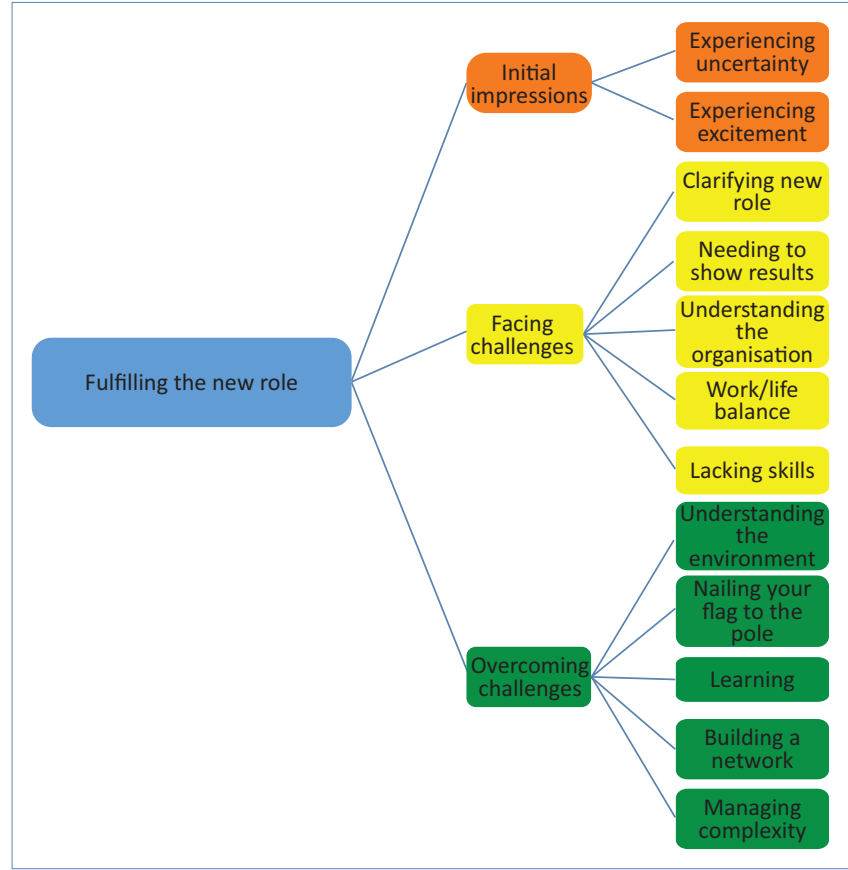

FIGURE 2: Key aspects of fulfilling a new leadership role. finally employed certain strategies in an attempt to overcome the challenges.

\section{Initial impressions}

Promotion into a senior leadership position can be thrilling and gratifying but also stressful as it deconstructs how we have known ourselves to be (Weinstock 2011). The initial impressions when stepping into a senior position were described by a newly promoted leader participating in this research as 'somewhat paradoxical' (P1). On the positive side it is seen as a personal and professional achievement; a milestone reached, associated with social prestige: 'I think that is how we're taught to recognise achievement in corporate life' (P1). It also affords leaders the opportunity to spread their wings and explore (P2), and it provides an opportunity to reshape relationships, build new networks and receive recognition (P3).

On the negative side many participants expressed a sense of anxiety relating to the unknown territory that came with the new position: '... that's nice to be promoted but flip, now what am I supposed to do?' (P1). This sense of foreboding stems from not knowing what was expected of them (P7), feeling uncertain about their level of competence and knowledge (P6), being unsure whether they would be able to fill the shoes of their predecessors (C3) and being unsure about the level of support they would receive from the organisation (P4). In some instances promotion was accepted for prestige and financial gain even though the individual knew that she was not 'cut out' for the new job (C1).

The anxiety experienced by some of the participants led to a lack of self-confidence and fear, as is evident from this statement from P6:

'I think my self-confidence was a bit shaken. Yes. Because it was totally something new and it included looking after a totally new environment, which I have never dealt with in the past. ... So, I had a lot of questions going through my mind to say 'Will I make it?' And I had fears'. (P6)

The fear, anxiety and self-doubt expressed by the participants are common phenomena among high achievers and can be attributed to a fear of failure (Argyris 1991; Manderscheid \& Ardichvili 2008). The notion of receiving support from the organisation featured prominently in a recent survey conducted by McKinsey \& Company (Martin 2015). The results showed that executives who successfully transitioned into the role received more support and resources from their organisations and were better able to spend their time and energy understanding the issues that they could influence as a result of their unique position (Martin 2015:1). It is thus clear that organisations have a role to play in micro-level support to ensure sustainability.

\section{Facing challenges}

The anticipation and speculation associated with the new leadership position soon turned into the harsh reality of 
performing in the new role when the incumbents realised that the realities of their situation differed considerably from their expectations (Freedman 2011). Failure in senior management positions is not uncommon and fulfilling the objectives of the role may be equally difficult, with one survey showing that less than one-third of transitioning executives reported having met all their objectives after 18 months in the position (Martin 2015). The main challenges faced by the participants in this study can be summarised as clarifying the new role, needing to show results, understanding the organisation, finding work-life balance and lacking skills.

One of the perhaps surprising findings of this research was that participants stated that they did not know exactly what was expected of them in the new role. When asked whether they knew exactly what was expected of them they responded:

'No. No it was, listen, this is the strategic direction, your role profile is sort of this, go and sort it out yourself'. (P4)

'So that was part of the stress of taking on that particular role and maybe that is so for many of the executives you'll interview that there's an expectation that you will define your agenda'. (P1)

C1 thought that newly promoted senior leaders were often expected to on-board themselves while C2 believed that organisations' intentions to support newly promoted leaders were good but that they lacked understanding of the challenges that the new leaders have to face.

While this expectation from organisations may be common, Kegan (1994) asserted that people are capable of managing only a certain level of complexity and that they require assistance to master the next level. Lack of support during transitions may result in emotional suffering (Kegan 1994). In this research it appeared that organisations were either not cognisant of this or ignored it. P7 expressed this lack of support as follows:

'When I talk to you about this I would never tell the outside world that this has been tough. Because hey, you don't cry about this stuff. You just knuckle down and somehow survive'. (P7)

HR2 described a very clinical process of handling newly promoted senior managers where, after the promotion, they 'pick it up on some type of system', and then proceeded to present a list of leadership training courses to the incumbent. There is a lack of individual emotional support. HR2 ascribed this state of affairs to the output-driven nature of organisations. She felt that HR practitioners were not enabled by business to provide better support for transitioning leaders.

This struggle of newly appointed leaders to understand exactly what is expected of them could be attributed to the higher level of complexity that is associated with senior roles and the expectation of organisations that the incumbents should have the ability to find their own way (Avolio \& Hannah 2008; Jaques 1996). However, for most of the participants the experience provoked anxiety. Hence, they felt that the organisation could have done more to support them and to provide clarity. One survey found that only $27 \%$ of transitioning executives who took part in that survey believed their organisations had the right resources or programmes in place to support their move into a C-level role (Martin 2015:2), thus supporting the views expressed by the participants in this research.

Perhaps as a result of their uncertainty or in combination with highly successful people's need to show their mettle, most participants had the desire to show results. However, here too they faced challenges such as not having access to the necessary resources (P4), focusing on the wrong goals (P1) and not doing enough to 'harvest the low-hanging fruit or early wins' (P8). This is in line with research that found that identifying where to secure early wins is one of the most important activities of a newly promoted senior leader (Lombardo \& Eichinger 2002; Watkins 2009). However, one participant (C1) observed that some of her clients put pressure on themselves to show early results and in the process moved too quickly, not fully understanding the ecosystem, with negative political results.

To be effective in their new role participants expressed the need to understand the systemic context of the role. They needed to understand the strategic intent of the organisation, the culture, politics, how decisions were made and where the power lay, or 'who's who in the zoo' (P4). Distinguishing between theory and practice is key, as expressed in the following quote:

'There's a theory of how we get things done in the business, how decisions are made through a steering committee or proposals or white papers and then there is the real way they get made and that's the politics'. (P1)

When a person is promoted from outside the organisation, understanding the culture of the new organisation is even more difficult. This may be compounded when the person moved from a different industry. One study found that successful senior managers spend more time learning about the organisational culture than those who are not successful but also warned that it is the most difficult aspect to understand (Martin 2015). This has been echoed by other research that emphasised the importance of understanding what the new role entails within the systemic context and organisational culture (Kaiser et al. 2011).

An important view that emerged from this research is the distinction between transitioning within an organisation (internal promotion) and transitioning from another organisation (external promotion). Participants expressed pros and cons associated with both. An internal promotion has the advantage that the person has prior knowledge of the organisational culture and politics (P4) and knows where the 'power base' is (P1). This inside-knowledge benefit extended to networking, with P8 indicating that relying on established relationships and networks is a way to get off to a flying start by depending more strongly on existing relationships initially. However, having already established 
relationships may come at a cost. In their new role, leaders take on new responsibilities that may put strain on existing relationships and they may be seen as 'the pebble in the shoe' (P2). M1 remarked that in certain instances existing relationships can come across as favouritism and have destructive consequences. The challenge is to view the relationships from the perspective of the new role and to redefine relationships where necessary (Charan et al. 2011).

Moving away from his former role was challenging for P7 because a replacement had not been appointed. He therefore straddled both old and new positions, unable to devote the required time to either. In C1's experience, newly promoted senior leaders often struggle with their peers now reporting to them while C3 considered this challenge to be the most significant one faced by newly promoted senior leaders. In addition, internally promoted leaders are often neglected in terms of organisational support because the assumption is made that they 'know their way around' (C1).

For P1, being promoted externally brought with it the luxury of settling in over time or a 'honeymoon period' of 60-90 days during which he was allowed to find his feet. He also experienced an element of forgiveness and the liberty to experiment, but this did not last indefinitely. Ultimately, the organisation has 'an expectation that you'll bring new ideas' (P5). Building a new network, getting to grips with the organisational culture and influencing people are also more of a challenge in external promotions (Lombardo \& Eichinger 2002; Watkins 2003).

For many participants stepping into a new role meant the realisation that they did not possess the necessary skills to perform the job. This is to be expected because promotion is associated with the need to acquire new skill sets (Bebb 2009; Freedman 2011). One caveat here, according to Watkins, is that managers in transition who rely too heavily on skills and strategies that worked for them in the past are setting themselves up for failure (Watkins 2009). In this research, the skills gap reported by the participants took on a number of forms. The notion of technical versus nontechnical skills played out in two ways. P6 was concerned that she now had to manage a group of engineers, of whose world she had very little knowledge. P1 experienced the opposite in that he came from a technical background but was now expected to manage people and 'felt quite ill equipped to do that'.

Part of managing people is the ability to delegate (Freedman 2011; Martin 2015). Some participants, especially the ones who performed the tasks themselves before, struggled with this. P6 struggled with the act of delegating whereas P3 struggled with the trust that is needed when delegating:

'Okay, so delegating is the easy part. It's staying out of it once you've delegated that I have a problem with [laughs]'. (P3)

According to Kets de Vries (2006), the need to develop advanced interpersonal and social skills is crucial to succeed at a senior level. In HR1's experience, the shift from being part of a team to leading the team and the interpersonal dynamics that accompany such a change are the most challenging aspects of a promotion. The demand on interpersonal skills was illustrated by one participant who had to take a tough stand and struggled:

'I had my first such a difficult conversation with a director. I became emotional, and, umm, I nearly walked out of his office. But then, at the same time, you know, the little voice in your head telling you if you walk out now, you've lost the plot. So, stick around and get through it'. (P2)

It is imperative for senior leaders to produce long-range strategies (Charan et al. 2011) and it is important to move from operational to strategic mode (Lombardo \& McCauley 1988). In the past, P7, though aware of the structural issues in the organisation, was able to ignore them. In the more senior role he now felt responsible for fixing these problems. C4 also observed her technically minded clients struggling to view the big picture. $\mathrm{C} 1$ and $\mathrm{C} 2$ identified the shift from operational to strategy as the most common problem in transitioning clients. HR2 cited the move from operational thinking to strategic thinking as the single biggest challenge faced by newly promoted senior leaders and the lack of time to think as one of the sources of this challenge.

Taking on a more senior position places demands on time availability. For P3, the new role led to longer working hours, which negatively impacted the time she could spend with her family. For P5, this led to a measure of personal distress, noting that some things had suffered. Giving up on previously meaningful activities such as exercising and losing one's routine are examples of this (P1).

It is clear from these findings that transitioning senior leaders faced significant challenges, experienced anxiety and felt ill equipped and not well supported.

\section{Overcoming challenges}

Role transitions are accompanied by a range of dynamic shifts that have an impact on the leader's internal and external realities (Bebb 2009; Manderscheid \& Ardichvili 2008; Weinstock 2011). A testimony to the resourcefulness of the participants in this research, and that is arguably partly the reason for their corporate success, is their ability to overcome the challenges presented by these shifting realities, despite the lack of organisational support in many cases. The individuals employed a number of different strategies: understanding the environment, 'nailing your flag to the pole', learning, building a network and managing the complexity.

The theme of facing challenges highlighted that many participants did not know what was expected of them and that they also had to make sense of how the organisation functioned. The importance of understanding the environment was highlighted by Watkins (2009) and Lombardo and Eichinger (2002), who asserted that executives in transition 
must gain a deep understanding of the situation at hand and adapt to that reality. To this end P1 insisted on defining key performance indicators to gain insight into what was expected of him. P4 took matters in his hands and through dialogue tried to understand what was expected of him. He described this process of managing upwards by having the following discussion with his manager:

'Listen, I know you don't know, but let's sit around the table and sort it out together ... 'Oh, you don't know...', so tough luck, I will go and sort it out myself'. (P4)

Although valiant from $\mathrm{P} 4$, this lack of support and clarity from his manager could have been a devastating blow to his achievements because one of the most critical aspects of senior leadership success is organisation-wide alignment (Martin 2015).

Some of the participants felt that to overcome the self-doubt and to prove to their managers that they were worthy of the new position, they had to show results quickly: '... it's important to nail your flag to the flag pole and say, this is what I did in my first 6 months' (P8). One way of achieving this is to be clear on one's intent (P2). There is a window of opportunity to show results, but it is important to understand the system before acting (C1). The notion of early wins is often punted in the literature (Watkins 2009), but a recent survey showed that most of the transitioning executives who took part in the survey indicated that it took them longer than 3 months to determine the solutions they required (Martin 2015). It would therefore seem that a balance between speed and patience is required.

To cope with their perceived or actual skills gap, participants set out to acquire knowledge. Learning and adaptability are considered the most important actions associated with career success at any level (Freedman 2011). While learning is an important aspect of growth, Argyris asserted that most companies not only have significant difficulty addressing what he calls the 'learning dilemma' but are often not even aware that it exists (Argyris 1991:99). According to M1, senior leaders must have sufficient domain knowledge: '... if people think you don't know, then they are going to try it on'. Newly promoted senior managers must be honest about their lack of domain knowledge and surround themselves with a set of trusted advisors in a transparent manner (M1).

For participants in this research learning took on two forms, formal and informal. Of the eight newly promoted leaders only one was exposed to a formal learning programme, which she claimed broadened her leadership capability (P6). A lack of formal learning opportunities was cited as a challenge by P1, who thought he may have benefitted from such an intervention. In terms of informal learning it was mostly a case of 'learning on the job' (P7). P8 explained that he did a significant amount of research before stepping into his new role. This research was focused on forming an idea of how top performers in the world managed a position similar to his. P1 employed a similar strategy:
'I tried to frame the work that I was doing against what a worldclass executive would be doing ... I read a lot about what C-level people do and I read blogs, articles written by successful people'. (P1)

The strategies that P7 and P8 chose should bode well for them because executives with the most successful transitions spend more time than others preparing for their roles, and they are 1.6 times as likely as others to report proficiency at the key skills for their jobs (Martin 2015). While some of the learning was conceptual and based on principles and approaches, other learning was more content and domain specific (P2). P5 joined an informal group that facilitated his learning. This gave him the opportunity to meet people from different fields, grappling with similar ideas.

All the participants cited building a strong network of the right people as crucial in navigating the new environment that came with their promotion, as illustrated by these quotes:

'If you've whispered in the ear of the CEO and that becomes his pet project then the decision is really made and you go through the mechanics of it'. (P1)

'So, how do we make decisions, who's the key stakeholder in such and such a department, who shouts the loudest, who should I listen to when they shout and who should [I] not?' (P8)

A network can span beyond the confines of the organisation. P2 found that enlisting the services of external experts such as consultants helped her to perform her job, while P3 created a colleague network that she used as a sounding board. Deciding who to include in one's network should not be limited to senior people or people with important titles, according to P4. Instead, one should also consider who the informal influencers are. This phenomenon has been illustrated by using social network analysis (Cross, Borgatti \& Parker 2002; Terblanche 2014). The process of building a network was a very conscious effort for P5, who used mapping software to create a map of international contacts that he considered important for his collaboration efforts. P8 scheduled one-on-one sessions with his new team (previous peers) to address any concerns they had. M1 has observed how recently promoted senior managers headhunted trusted subordinates from their previous organisations in order to create a strong network in their new environment. M1 also warned of the dangers of selecting the 'wrong' mentors and support networks: when a newly promoted senior manager sides with a prominent senior person who gets sidelined or who leaves the organisation, the support structure effectively falls away, leaving the newly promoted senior manager exposed.

In terms of network building and establishing a relationship with the new team reporting to the newly promoted senior manager, successful executives indicated that they relied heavily on their initial team and direct reports as a source of their success (Martin 2015). In building his team, P4 found that talking to the team was not sufficient. He had to actually listen to them in order to get to know them. Regular communication and obtaining the team's buy-in assisted P6 to build a strong team who trusted him. When things went wrong, P3 took a hit 
for the team by being 'the face of the non-delivery' and this helped to unite the team and deepen mutual trust. This process of clarifying the team's role within the larger organisational context is considered to be one of the primary tasks of a newly promoted senior leader (Freedman 2011).

The levels of complexity that leaders have to deal with increase substantially in a senior role and senior leaders' ability to cope at higher levels is linked to their ability to perceive and manage complexity (Rooke \& Torbert 2005). Participants employed various strategies to manage the higher levels of complexity, as illustrated below:

'So, the skill to acquire or learn is to see the complexity and reduce it to simplicity'. (P1)

'I use simple pictures to reduce complexity to simple terms. What I try to do is have people on my team that could deal with the complexity'. (P3)

The participants interviewed in this research faced significant challenges during the transition into their senior leadership roles. They employed various strategies to cope, often as a result of lacking organisational support. These findings are echoed by Freedman, who asserted that greater structure and support are needed to help leaders cope with the challenges of upward transition (Freedman 2011).

\section{Limitations of the study}

This research focused on the challenges that recently promoted senior managers experienced in their new roles and the coping mechanisms they employed. More research is required on the available personal and organisational support mechanisms of such leaders and how best to apply these for each of the given challenges.

\section{Conclusion}

In the current South African organisational context, change and transformation are imperative and a reality. For sustainable development and transformation to occur, strong leadership is required. When leaders are promoted into senior positions they are vulnerable and face the possibility of failure, with negative implications on both micro (individual) and macro (organisational) levels. For leaders to transition successfully, organisations need to understand what challenges transitioning leaders face in order to provide adequate developmental support.

This study highlighted the plethora of challenges transitioning leaders face on a personal and systemic level. These challenges included the following:

- uncertainty regarding expectations

- pressure to show early results

- lack of understanding of organisational politics if externally promoted

- disruption in work-life balance

- lack of specific skills demanded in the new role.
This research also highlighted the fact that participants felt ill prepared to face these challenges and were often disillusioned and overwhelmed. In this regard, their coping strategies included the following:

- actively endeavouring to understand organisational functioning

- determining where power bases lie

- securing short-term successes

- learning new skills and acquiring domain knowledge

- building a strong network of trusted people

- learning to manage higher levels of complexity.

When moving into a senior position within complex organisations it would be reasonable to expect an individual to experience a degree of discomfort and to undergo learning. This research, however, exposed the general lack of organisational support and clarity on what is expected of newly promoted senior leaders. This lack of support seemed to have contributed disproportionality to the anxiety experienced by the participants in this research.

The findings of this research have implications for organisations and transitioning leaders. Transitioning leaders could prepare themselves for the career move by educating themselves on the types of challenges they are likely to face; seeking clarity on what is expected of them in the new role; and actively building a support network. Organisations, in the form of line managers and HR representatives, could support transitioning leaders by providing the relevant information they require to navigate the new role; explaining the cultural dynamics of the organisation; exposing transitioning leaders to tailor-made leadership development programmes; providing coaching and mentoring support; and assisting the incumbent to set realistic expectations of delivering early results.

For responsible and ethical transformation, it is crucial to address both micro-level and macro-level aspects and to ensure development and support. Ensuring the successful transition of organisational leaders into senior positions in corporate South Africa may provide the glue on a micro level to ensure sustainable developmental success on the macro level.

\section{Acknowledgements Competing interests}

The authors declare that they have no financial or personal relationships which may have inappropriately influenced them in writing this article.

\section{Authors' contributions}

N.H.D.T. conducted the research and wrote the article. R.M.A. and S.V.C.P. supervised the project and edited the final draft. 


\section{References}

Adler, P. \& Kwon, S., 2002, 'Social capital: Prospects for a new concept', Academy of Management Review 27(1), 17-40.

Argyris, C., 1991, 'Teaching smart people how to learn', Harvard Business Review 69(3), 99-109

Avolio, B.J. \& Gardner, W.L., 2005, 'Authentic leadership development: Getting to the root of positive forms of leadership', The Leadership Quarterly 16(3), 315-338. https://doi.org/10.1016/j.leaqua.2005.03.001

Avolio, B.J. \& Hannah, S.T., 2008, 'Developmental readiness: Accelerating leader development', Consulting Psychology Journal: Practice and Research 60(4) 331-347. https://doi.org/10.1037/1065-9293.60.4.331

Bebb, S., 2009, 'The structure of role transition: A phenomenological study of successful executives from five countries', International Journal of Leadership Studies 4(2), 223-243.

Bettin, P.J. \& Kennedy, J.K., 1990, 'Leadership experience and leader performance: Some empirical support at last', The Leadership Quarterly 1(4), 219-228. https:// doi.org/10.1016/1048-9843(90)90002-Y

Boyce, L.A., Zaccaro, S.J. \& Wisecarver, M.Z., 2010, 'Propensity for self-developmen of leadership attributes: Understanding, predicting, and supporting performance of leader self-development', The Leadership Quarterly 21(1), 159-178. https:// doi.org/10.1016/j.leaqua.2009.10.012

Bradford, J., 1995, 'Role change: Are you wasting talent?', Management Development Review 8(6), 1-4. https://doi.org/10.1108/09622519510772068

Burger, R., Steenkamp, C.L., Van der Berg, S. \& Zoch, A., 2015, 'The emergent middle class in contemporary South Africa: Examining and comparing rival approaches', Development Southern Africa 32(1), 25-40. https://doi.org/10.1080/0376835X 2014.975336

Charan, R., Drotter, S. \& Noel, J., 2011, The leadership pipeline, Wiley, San Francisco, CA.

Charmaz, K., 2014, Constructing grounded theory, Sage, Thousand Oaks, CA.

Chevalier, S., 2015, 'Food, malls and the politics of consumption: South Africa's new middle class', Development Southern Africa 32(1), 118-129. https://doi.org/10.10 80/0376835X.2014.965388

Cross, R., Borgatti, S.P. \& Parker, A., 2002, 'Making invisible work visible: Using social network analysis to support strategic collaboration', California Management Review 44(2), 25-46. https://doi.org/10.2307/41166121

Day, D. \& Antonakis, J., 2012, The nature of leadership, Sage, Thousand Oaks, CA.

Day, D., Fleenor, J., Atwater, L., Sturm, R. \& McKee, R., 2014, 'Advances in leader and leadership development: A review of 25 years of research and theory', The Leadership Quarterly 25(1), 63-82. https://doi.org/10.1016/j.leaqua.2013. 11.004

Denton, J.M. \& Van Lill, J.B., 2006, 'Managerial derailment', Vilakshan, XIMB Journal of Management 3, 231-250.

Dotlich, D.L., Noel, J.L. \& Walker, N., 2004, Leadership passages, Wiley, San Francisco, CA.

Freedman, A.M., 2011, 'Some implications of validation of the leadership pipeline concept: Guidelines for assisting managers-in-transition', The PsychologistManager Journal 14(2), 140-159. https://doi.org/10.1080/10887156.2011. 570146

Goleman, D., 1996, Emotional intelligence: Why it can matter more than IQ Bloomsbury, London.

Glaser, B. \& Strauss, A., 1967, The discovery of grounded theory: Strategies for qualitative research, Aldine Publishing, Chicago, IL.

Goulding, C., 2002, Grounded theory a practical guide for management, business and market researchers, Sage, Thousand Oaks, CA.

Isopahkala-Bouret, U., 2008, 'Transformative learning in managerial role transitions', Studies in Continuing Education 30(1), 69-84. https://doi.org/10.1080/0158 0370701841556

Jaques, E., 1996, Requisite organisation, Cason Hall, Gloucester, MA.
Kaiser, R.B., Craig, S.B., Overfield, D.V. \& Yarborough, P., 2011, 'Testing the leadership pipeline', The Psychologist-Manager Journal 14, 76-91. https://doi.org/10.1080/ pipeline,
10887156.2011 .570137

Kegan, R., 1994, In over our heads: The mental demands of modern life, Harvard University Press, Cambridge, MA.

Kets de Vries, M.F.R., 2006, The leadership mystique: Leading behavior in the human enterprise, FT Prentice Hall, London.

Khunou, G., 2015, 'What middle class? The shifting dynamic nature of class position', Development Southern Africa 32(1), 90-103. https://doi.org/10.1080/0376835X 2014.975889

Lincoln, Y. \& Guba, E., 1985, Naturalistic inquiry, Sage, Newbury Park, CA.

Lombardo, M. \& Eichinger, R.W., 1995, Preventing derailment: What to do before it's too late, Center for Creative Leadership, Greensboro, NC.

Lombardo, M. \& McCauley, C., 1988, The dynamics of leadership derailment, Centre for Creative Leadership Development, Greensboro.

Lombardo, M.M. \& Eichinger, R.W., 2002, The leadership machine: Architecture to develop leaders for any future, Lominger Limited, Inc, Minneapolis, MN.

Manderscheid, S. \& Ardichvili, A., 2008, 'A conceptual model for leadership transition', Performance Improvement Quarterly 20(1), 113-129. https://doi.org/10.1002/ piq.20006

Martin, J.-F., 2015, Ascending to the C-suite, McKinsey \& Company, New York.

McCall, M. \& Lombardo, M., 1983, Off the track: Why and how successful leaders get derailed, Centre for Creative Leadership, Greensboro, NC.

Mezirow, J., 1994, 'Understanding transformation theory', Adult Education Quarterly 44(4), 222-232. https://doi.org/10.1177/074171369404400403

Mezirow, J., 2000, Learning as transformation: Critical perspectives on a theory in progress, Jossey-Bass, San Francisco, CA.

Morrison, A., White, R. \& Van Velsor, E., 1987, Breaking the glass ceiling: Can woman make it to the top? Addison-Wesley, Reading, MA.

Mumford, T.V., Campion, M.A. \& Morgeson, F.P., 2007, 'The leadership skills strataplex: Leadership skill requirements across organizational levels', The Leadership Quarterly 18(2), 154-166. https://doi.org/10.1016/j.leaqua.2007.01.005

Peltier, B., 2010, The psychology of executive coaching: Theory and application, 2nd edn., Routledge, New York.

Poutiatine, M.I., 2010, 'What is transformation? Nine principles toward an understanding of the transformational process for transformational leadership' Journal of Transformative Education 7(3), 189-208. https://doi.org/10.1177/ 1541344610385249

Rooke, D. \& Torbert, W., 2005, 'Seven transformations of leadership', Harvard Business Review 83(4), 66-76.

Scandura, T.A. \& Lankau, M.J., 1996, 'Developing diverse leaders: A leader-member exchange approach', The Leadership Quarterly 7(2), 243-263. https://doi. org/10.1016/S1048-9843(96)90043-0

Strauss, A. \& Corbin, J., 1990, Basic qualitative research: Grounded theory procedures and techniques, Sage, Newbury Park, CA.

Sutton, J., 2008, 'Coaching leadership transitions', in J.L. Noel \& D.L. Dotlich (eds.), The 2008 Pfeiffer annual leadership development, pp. 199-207, Wiley, Hoboken, NJ.

Terblanche, N., 2014, 'Knowledge sharing in the organizational context: Using social network analysis as a coaching tool', International Journal of Evidence Based Coaching and Mentoring 12(2), 146-164.

Visagie, S. \& Koekemoer, E., 2014, 'What it means to succeed: Personal perceptions of career success held by senior managers', South African Journal of Business Management 45(1), 43-54.

Watkins, M.D., 2003, The first 90 days: Critical success strategies for new leaders at all levels, Harvard Business School Press, Boston, MA.

Watkins, M.D., 2009, 'Picking the right transition strategy', Harvard Business Review $87(1), 46-53$.

Weinstock, B., 2011, 'The hidden challenges in role transitions and how leadership coaching can help new leaders find solid ground', Holistic Nursing Practice 25(4), 211-214. https://doi.org/10.1097/HNP.0b013e31822270ec 